\title{
Proteção social em saúde: um balanço dos 20 anos do SUS
}

| 'Ana Luiza D'Ávila Viana, ${ }^{2}$ Cristiani Vieira Machado |

Resumo: A instituição do Sistema Único de Saúde pela Constituição brasileira de 1988, baseado na diretriz de universalidade e inserido em uma lógica abrangente de Seguridade Social, representou uma inflexão importante na trajetória histórica da proteção social em saúde no país. $\mathrm{O}$ artigo parte de um debate conceitual sobre proteção social em saúde e da discussão sobre a trajetória e as principais características histórico-estruturais do sistema de proteção social brasileiro conformado até os anos 1980, com ênfase nas suas expressões na saúde. A seguir, procura fazer um balanço dos 20 anos do SUS, a partir da análise das mudanças e continuidades observadas em quatro dimensōes selecionadas para a caracterização da proteção social em saúde no caso brasileiro: organização institucional; financiamento; mix público-privado e modelo de atenção em saúde. Por fim, discutem-se as principais dificuldades e os desafios atuais relacionados à expansão da proteção social em saúde no Brasil.

\author{
${ }^{1}$ Economista; doutora em \\ Economia pela Unicamp; \\ professora adjunta no \\ Departamento de Medicina \\ Preventiva e Social da \\ Universidade de São Paulo. \\ Endereço eletrônico: \\ anaviana@usp.br. \\ ${ }^{2}$ Médica sanitarista; doutora \\ em Saúde Coletiva pelo IMS- \\ UERJ; professora e \\ pesquisadora no Departamento \\ de Administração e \\ Planejamento em Saúde da \\ ENSP-Fiocruz. \\ Endereço eletrônico: \\ cristiani@ensp.fiocruz.br.
}


A instituição do Sistema Único de Saúde (SUS) pela Constituição brasileira de 1988, baseado na diretriz de universalidade e inserido em uma lógica abrangente de Seguridade Social, representou uma inflexão importante na trajetória histórica da proteção social em saúde no país. Como assinalaram Viana e Dal Poz (1998), tal momento representou uma reforma do tipo big bang, por introduzir em curto espaço de tempo alterações significativas nos fundamentos e nas bases institucionais de estruturação da política e do sistema público de saúde.

Nos vinte anos que se seguiram à Carta Constitucional, a implementação do SUS trouxe mudanças em várias dimensões relevantes para a caracterização da proteção social, compreendida como a forma de articulação entre Estado, mercados e sociedade para proteger os cidadãos dos riscos associados aos efeitos socialmente diferenciadores do mercado em um dado contexto histórico. No cerne dessas mudanças estiveram as tensões relacionadas à luta pela concretização da saúde como direito de cidadania, principal bandeira da reforma sanitária brasileira.

Apesar dos avanços concretos em termos político-institucionais e de expansão do acesso da população às ações e serviços de saúde, o sistema de saúde brasileiro, duas décadas após a Constituição, ainda apresenta problemas sérios, incoerentes com os preceitos da Seguridade e do SUS.

Se a expressão última dessas distorções é a persistência de graves desigualdades em saúde, registradas sob várias perspectivas de análise - do gasto social, do acesso aos serviços, dos resultados sanitários, entre outros - um balanço da política no período exige uma análise cuidadosa das características do sistema de saúde que se mostram incompatíveis com uma lógica de proteção social abrangente, tal como havia sido defendida pelo movimento sanitário. Ademais, requer a consideração dos fatores histórico-estruturais e conjunturais que influenciaram a situação atual da política pública de saúde no país, muitos dos quais extrapolam os limites setoriais. Afinal, em que medida as mudanças observadas no sistema de saúde nos últimos vinte anos transformaram efetivamente as características da proteção social em saúde no Brasil?

Este artigo procura fazer um balanço dos vinte anos do SUS, a partir da análise das mudanças e continuidades observadas em dimensões selecionadas para a caracterização da proteção social em saúde no caso brasileiro. Para isso, parte de uma discussão conceitual sobre proteção social em saúde. A seguir, aborda 
brevemente a trajetória e as principais características histórico-estruturais do sistema de proteção social brasileiro conformado até os anos 1980, com ênfase nas suas expressões na saúde. $\mathrm{O}$ quarto tópico do texto faz uma análise das principais transformações e dificuldades observadas nos últimos vinte anos em quatro eixos relevantes para a proteção social em saúde: organização institucional; financiamento; mix público-privado e modelo de atenção em saúde. Por fim, discutem-se os desafios atuais relacionados à expansão da proteção social em saúde no Brasil.

\section{Proteção social em saúde: aspectos teóricos e históricos}

Os modernos sistemas de proteção social no século XX surgiram para atenuar as diferenças sociais criadas pelo livre funcionamento do mercado, principalmente as diferenças de salários, renda e consumo e que são sempre repostas pelos diferentes momentos de funcionamento dos mercados e causa da produção de desigualdades (os mercados auto-regulados, como afirmou Polanyi), o que podemos ver com clareza nesse momento de esgotamento de um determinado padrão de crescimento econômico. Como se sabe, a dinâmica capitalista produz simultaneamente dois processos de natureza distinta: o da homogeneização social, cuja base é o assalariamento de massa, e o de reiteração da heterogeneidade, quando o mercado fomenta a produção de diferenças sociais.

A forma criada para proteger os cidadãos desses movimentos de produção de desigualdades e de insegurança social foi a assunção pelo Estado, principalmente após a Segunda Guerra Mundial, do financiamento e provisão de um grande número de bens e serviços que os cidadãos não poderiam acessar única e exclusivamente pela renda obtida pelo trabalho, ou quando sem trabalho necessitassem desses bens, como é o caso da saúde. À estrutura de produção de bens e serviços sociais, Robert Castel deu o nome de propriedade social, para diferenciar da propriedade individual responsável pela liberdade/autonomia do homem na virada da modernidade e base fundamental das idéias liberais.

Esse movimento de criação de estruturas e subsistemas de proteção social, atuando de forma conjunta e sinérgica, foi a grande conquista do século XX, quando se conseguiu que o social e o econômico se conjugassem em favor de uma maior igualdade e integração social, de forma a neutralizar os riscos sociais criados pelos processos acelerados de industrialização/urbanização e advindos do ciclo econômico em vários períodos do século passado. 
Como afirmaram vários autores, no decorrer de todo o milênio anterior, e agora com ênfase maior, não é mais necessário insistir no caráter disruptivo da forma mercantil da diferenciação social, pois nela se enraízam fortes riscos que rasgam o tecido social e ameaçam a coesão da sociedade. A grande novidade no Pós-Guerra foi ter imposto um particular mecanismo de freio às forças brutas da desigualdade socialmente produzidas pelo mercado através do sistema de direitos e políticas sociais.

A política de saúde se insere fortemente nesse movimento de subtrair da órbita mercantil o acesso aos bens e serviços de saúde, quando a responsabilidade pela saúde de uma determinada população passa a ser responsabilidade de todos, coletiva, e um direito do cidadão. Dessa forma a reprodução social passa a ser regida por leis construídas fora da órbita pura e simples do mercado, e sim pela extensão e profundidade alcançada pelo sistema de políticas sociais integrantes do Estado Social/ Welfare State.

Somente assim pode-se garantir aos que estão incluídos na condição salarial e aqueles que são recorrentemente relegados dela, direito às condiçôes básicas de vida e inclusão e manutenção na sociedade e, por isso mesmo, a proteção social e o sistema de políticas e direitos sociais nela criados são a própria regulação social do capitalismo avançado (DRAIBE, 1997).

É importante ressaltar que a proteção social não consegue sempre ou nunca suprimir a pobreza e instaurar a plena igualdade, pois as mesmas serão repostas pelos diferentes momentos do ciclo econômico e agravadas quando esses processos forem totalmente auto-regulados. No decorrer do século XX, diferentes sistemas de proteção social foram construídos, alguns mais cedo do que outros, uns mais extensos e integrados, como os da Europa do Norte frente aos do Sul, e os de nosso continente, muito tardiamente, e mesmo assim com fortes distorções, alto grau de segmentação, forte fragmentação institucional e baixo poder de participação e regulação social.

Conhecer as razões dessas diferenças e as especificidades de cada modelo frente a uma determinada realidade social e histórica foi um esforço imenso de investigação que iniciou nos anos 50 e prossegue até os dias atuais, e no Brasil teve maior densidade nas décadas de 70 e 80 do século passado. Os principais tipos de estudos sobre políticas públicas foram feitos para explicar o surgimento de um grupo de políticas públicas voltadas para a proteção social dos indivíduos, constituídas já no século XX e conhecidas como políticas sociais. A importância 
de retratar esses tipos de estudos explica-se pelo fato de as políticas de saúde terem sido conformadas nesse longo processo de constituição dos modernos sistemas de proteção social, no período de conformação das sociedades modernas. Muitas das análises de políticas de saúde em vários países são decorrentes de estudos mais gerais e os grandes tipos de políticas públicas - universais ou ocupacionais - servem para definir um padrão geral de proteção social ou de políticas setoriais, como as de saúde, educação, previdência e assistência.

Tais estudos mobilizaram diferentes explicações sobre as origens e desenvolvimento dos Estados de Bem-Estar Social, surgidos a partir da implementação das políticas sociais nos meados do século XX. As explicações podem ser agrupadas de diferentes formas: pelo peso das variáveis explicativas (econômicas, políticas e institucionais); pelas correntes de pensamento ou uso de referenciais teóricos (marxistas, pluralistas, institucionalistas), ou ainda pelo tipo de argumento explicativo e/ou linha metodológica de análise (modelo de cobertura, estatismo e desmercantilização).

O primeiro modelo explicativo quanto à origem e desenvolvimento dos Estados de Bem-Estar Social pode ser visto a partir de três fontes explicativas: a contextualista (variáveis econômicas), a política e a institucionalista. Nesse caso, o que se privilegia é mais o argumento explicativo que a adoção de um modelo preestabelecido de referencial teórico. A segunda forma explicita o referencial teórico, ligado às grandes escolas de pensamento, e finalmente, pode-se pensar em outro tipo de ordenamento, como o proposto por Girotti (2000), valorizando mais um método específico de análise do que um argumento ou uma referência teórica singular, podendo estar mais ou menos apoiada em uma ou outra escola de pensamento.

O quadro 1 resume o surgimento do Estado de Bem-Estar Social, segundo as diferentes formas de agrupar argumentos, escolas de pensamento e métodos.

O leitor atento vai se dar conta de que alguns argumentos se repetem, ora pelas escolas, outras vezes pelos argumentos explicativos, ou ainda pelo método específico de análise. Isto porque as escolas de pensamento utilizam também as variáveis explicativas e alguns dos métodos expostos. Exemplo: a teoria marxista também desenvolveu, principalmente por seus teóricos mais modernos, inúmeras explicações (de fenômenos) baseadas no processo de mercantilização/desmercantilização de diferentes objetos e relações, não sendo a única que privilegia esse processo específico mo constitutivo das sociedades modernas. 
Quadro 1 - Explicação das políticas de proteção social pelo peso das variáveis, referencial teórico e linha metodológica de análise.

\begin{tabular}{|c|c|c|c|}
\hline \multirow{2}{*}{$\begin{array}{l}\text { Peso das Variáveis } \\
\text { explicativas }\end{array}$} & Econômicas & \multirow[b]{2}{*}{$\begin{array}{l}\text { Políticas } \\
\text { As políticas sociais expressam os } \\
\text { processos de mobilização social e } \\
\text { política demandando proteção } \\
\text { social frente aos riscos crescentes } \\
\text { das sociedades urbanas. Quanto } \\
\text { maior for o poder de mobilização } \\
\text { dessas demandas mais proteção se } \\
\text { atingirá. }\end{array}$} & Institucionais \\
\hline & $\begin{array}{l}\text { As políticas sociais são } \\
\text { relacionadas às exigências dos } \\
\text { processos de urbanizaçäo e } \\
\text { industrialização. Quanto mais } \\
\text { precoce é o processo de } \\
\text { industrializaçăo e urbanização } \\
\text { mais precoce será o sistema } \\
\text { protetor. }\end{array}$ & & $\begin{array}{l}\text { O ambiente cultural e } \\
\text { institucional de um } \\
\text { determinado país e a origem } \\
\text { das instituições ligadas à } \\
\text { proteção social determinam os } \\
\text { modelos de proteção social. } \\
\text { Quanto maior o peso das } \\
\text { diferentes instituições - } \\
\text { estatais, filantrópicas, privadas } \\
\text { e religiosas - na conformação } \\
\text { das políticas sociais, maior a } \\
\text { probabilidade de se } \\
\text { constituírem modelos públicos } \\
\text { ou privados ou ainda um mix } \\
\text { de modelos. }\end{array}$ \\
\hline \multirow{2}{*}{$\begin{array}{l}\text { Correntes de } \\
\text { pensamento }\end{array}$} & Marxismo & \multirow[b]{2}{*}{$\begin{array}{l}\text { Pluralismo } \\
\text { A proteção social é fruto da } \\
\text { organização dos grupos e das } \\
\text { mobilizações que ensejam no } \\
\text { sentido de resolver os problemas } \\
\text { de diferenciação que acompanham } \\
\text { a modernização da sociedade. }\end{array}$} & Institucionalismo \\
\hline & $\begin{array}{l}\text { A proteção social vincula-se ao } \\
\text { surgimento do capitalismo e a } \\
\text { luta de classes que ele enseja. } \\
\text { É indispensável para garantir o } \\
\text { desenvolvimento capitalista } \\
\text { (reprodução da força de } \\
\text { trabalho) e para regular os } \\
\text { conflitos de classe. }\end{array}$ & & $\begin{array}{l}\text { A proteção social funda-se no } \\
\text { curso do desenvolvimento das } \\
\text { instituiçōes constitutivas da } \\
\text { política social. } \\
\text { São os propósitos de } \\
\text { constituição das instituiçōes } \\
\text { presentes na política social que } \\
\text { explicam a natureza e } \\
\text { abrangência da proteção social. }\end{array}$ \\
\hline \multirow{2}{*}{$\begin{array}{l}\text { Linha metodológica } \\
\text { de análise }\end{array}$} & \multirow[b]{2}{*}{$\begin{array}{l}\text { Modelo de cobertura } \\
\text { O modelo de cobertura vê a } \\
\text { decisão sobre quem proteger } \\
\text { como sendo a decisão fundante } \\
\text { dos sistemas de proteção social } \\
\text { e da qual decorrem as demais } \\
\text { (quanta proteção oferecer e } \\
\text { como oferecer essa proteção). }\end{array}$} & \multirow[b]{2}{*}{$\begin{array}{l}\text { Estatismo } \\
\text { O estatismo repõe o papel do } \\
\text { Estado e seu grau de influência nas } \\
\text { configurações da proteção social. } \\
\text { Ele passa a ser visto como } \\
\text { elemento central para explicar a } \\
\text { emergência e desenvolvimento do } \\
\text { estado de bem estar social. }\end{array}$} & Desmercantilização \\
\hline & & & $\begin{array}{l}\text { A política social é uma reação } \\
\text { contra a ameaça colocada pela } \\
\text { subordinação da existência } \\
\text { individual aos efeitos do } \\
\text { mercado e ela se constitui por } \\
\text { uma série de medidas cujo } \\
\text { objetivo final é } \\
\text { desmercantilizar o acesso aos } \\
\text { bens e serviços sociais. }\end{array}$ \\
\hline
\end{tabular}

Fonte: Elaboração das autoras.

Entretanto, os estudos mais recentes se caracterizam por combinar vários elementos explicativos, em determinado período histórico, em detrimento daqueles que elegem uma única causa para explicar um determinado fenômeno, sem uma preocupação explícita por se filiar a uma ou outra corrente de pensamento.

Como exemplo de um modelo multicausal, podemos citar o de Maurizio Ferrera, em obra seminal que privilegia a dinâmica genética e a transformação dos diversos sistemas de proteção social, ressaltando específicas configurações históricas de problemas, recursos e cultura administrativa que respondem pelas estratégicas e lógicas de funcionamento dos Estados de Bem-Estar Social e que são diferentes de contexto para contexto. 
Segundo Ferrera (1993), os processos de modernização, industrialização, urbanização, democratização e expansão do mercado capitalista compõem o contexto geral que justifica a emergência do Estado de Bem-Estar Social, mas não como sua causa primeira e única. A formação do Estado de Bem-Estar Social não depende tão-somente das relações de poder entre classes sociais, mas de uma complexidade de fatores, tais como: ideologia das elites, compromissos entre o próprio bloco de poder dominante, tipo de pessoal burocrático, ambiente cultural e institucional do país, além da diversidade de orientaçôes culturais das elites administrativas e da herança das políticas na área social.

Desta forma, as análises da formação dos diferentes tipos de Estado de Bem-Estar Social devem abranger a pluralidade de fatores que, historicamente, condicionaram sua evolução, através da utilização e combinação dos instrumentos clássicos das análises contextualista, institucionalista e política. Ainda segundo Ferrera, a formação do Estado de Bem-Estar Social é um processo político, cuja origem pode estar na crise das políticas públicas, consubstanciada em velhas soluções para novos problemas.

Utilizando esses enfoques analíticos, há um grande consenso sobre os tipos mais comuns de proteção social, o modelo universal e o ocupacional/meritocrático, distinguindo-se um do outro pela resposta que deram a quem proteger e como financiar essa proteção: no modelo universal todos serão cobertos e a forma de financiamento é via impostos públicos; já no modelo ocupacional, somente serão protegidos os trabalhadores inseridos no mercado formal de trabalho e o financiamento da provisão será feito com aportes e contribuições de trabalhadores, empregadores e, às vezes, do Estado. As razões para a adoção de um ou outro modelo guardam coerência com o grau de heterogeneidade social, o papel das instituições nos antigos modelos de proteção social, a força dos movimentos e partidos social-democratas ou socialistas, o papel das idéias e as formas de difusão das mesmas pelas elites etc.

Porém, foi a partir da Segunda Grande Guerra que muitos países iniciaram o desenvolvimento de seus sistemas de proteção, com modelos mais ou menos abrangentes, sendo que a Europa continental adotou o modelo corporativo/ meritocrático e a Europa do Norte, o modelo universal. Os denominados Estados de Bem-Estar Social ou Welfare State tiveram trinta anos gloriosos de expansão, o que foi acompanhado por um efetivo desenvolvimento dos sistemas de saúde. Se 
nesses primeiros anos a principal tônica dos estudos da política social refletia a intenção de entender o fenômeno, a partir de meados dos anos 1970 há uma inflexão frente ao contexto de crise econômica dos Estados, trazendo à tona a preocupação com a sustentabilidade política e econômica do próprio Welfare. Ganham maior expressão os estudos relacionados à economia política com o foco nos determinantes do gasto público.

A crise dos sistemas de proteção social nas décadas de 70 e 80 do século passado induziu a um processo de discussão dos modelos adotados, gerando propostas para a reforma dos sistemas. A agenda principal do debate passou a ser o ajuste fiscal, a globalização dos mercados e a política para contenção dos custos.

O setor saúde começou a ser entendido dentro do modelo protetor como a área gastadora e ineficiente na gestão dos recursos. O fato é que no correr da segunda metade do século XX os sistemas de saúde tornaram-se cada vez mais complexos num contexto de transformações nos perfis de saúde e doença, de mudança populacional e crescente incorporação tecnológica (transição epidemiológica, demográfica e revolução tecnológica). Em três décadas, o setor saúde passou a ocupar um papel de destaque na economia dos países, gerando emprego, demandando investimento, movimentando boa parcela de recursos dos Estados. No contexto da política de proteção, o setor saúde configurava-se como uma área crítica, seja pela sua vertiginosa expansão no período, seja pela perspectiva de manutenção desse mesmo padrão nos anos subseqüentes.

É assim que também a partir dos anos 1970 têm início os estudos mais específicos sobre a análise da política de saúde em diferentes países, como o trabalho de Leichter (1979), com uma análise comparada da assistência à saúde em quatro nações; o estudo de Enthoven (1985), com reflexões sobre a administração do Sistema Nacional de Saúde; e a análise de Ashford (1986) sobre os sistemas de seguridade inglês e francês.

Ainda na década de 1980, a crítica ao gasto em saúde foi associada à discussão sobre o uso ineficiente dos recursos, iniqüidade do acesso e qualidade dos serviços de saúde. Cresce a partir de então a tendência de estudos de análise da política de saúde de caráter instrumental, referentes ao campo estrito da avaliação, incluindo temas sobre efetividade, eficácia e eficiência das políticas. A ênfase se dá, portanto, no exame da reengenharia institucional e dos traços constitutivos dos programas e seus resultados, em detrimento de discussões sobre o processo 
político na construção de modelos e prioridades em saúde (estudos sobre a formulação e implementação de políticas). O referencial teórico da avaliação em saúde, com forte influência do pensamento epidemiológico, passa a contribuir nas análises sobre as políticas da saúde.

As propostas de reforma dos sistemas de saúde ganham difusão nos diversos países especialmente a partir dos anos 1980, com a entrada do Banco Mundial no debate da saúde. Até então a OMS (criada em 1946 com o objetivo de constituir uma única instituição intergovernamental de saúde orientadora da política de saúde para os países) exercia o papel de liderança no debate da política de saúde, contribuindo com os Estados-membros no desenvolvimento de normas práticas para os sistemas nacionais de saúde. Na década de 1970 a OMS exerceu importante papel na orientação da política com a realização em 1978 da Conferência de AlmaAta e o lançamento do projeto "Saúde para todos no ano 2000", divulgando a proposta de Cuidados Primários em Saúde (MATTA, 2005).

Durante a década de 1980, o Banco Mundial passa a assumir um papel mais incisivo na discussão da política da saúde, afinando-se ao debate da economia da saúde e produzindo relatórios de discussão setorial na perspectiva da racionalização e maior eficiência na utilização dos recursos, indicando a necessidade de ajustes econômicos e estruturais do setor saúde, com o financiamento da atenção pelo capital privado e a crítica contundente à universalidade do acesso à saúde (WORLD BANK, 1993). Contudo, enquanto os países desenvolvidos discutiam a crise do sistema protetor e alternativas de reforma, com clara resistência às propostas de abertura e modificação estrutural de seus modelos, os demais países do mundo iniciavam seus processos de construção dos sistemas de proteção e de saúde. A difusão de idéias reformistas e o diagnóstico de insustentabilidade econômica dos sistemas de bem-estar surgiam como um freio à construção de novos sistemas protetores nos países em desenvolvimento.

Mais recentemente, Freeman e Moran (2000) observam que a especificidade da política de saúde precisa ser considerada na análise das reformas nos países e de seu desenvolvimento futuro. Os autores ressaltam que existem pelo menos três dimensões na configuração dos sistemas de saúde dos modelos protetores que atuam como forças resistentes aos processos de reforma: a dimensão econômicoindustrial, a dimensão política e a dimensão de proteção social. Estas dimensões retratam a importância da saúde no contexto dos sistemas de proteção social e 
compreendem importantes aspectos de sustentação dos modelos frente ao processo de reforma dos sistemas de saúde que teve início nos anos 70 .

Por outro lado, a identificação destas dimensões permite a visualização da suscetibilidade dos países que iniciam seus modelos de proteção, porque as dimensões de seus sistemas são por si só fragilizadas. Na dimensão da proteção social há um caminho a trilhar no reconhecimento dos direitos de cidadania; na dimensão política há um processo de maturação institucional dos diferentes agentes e atores que transitam no processo político; na dimensão econômica há uma fragilidade da indústria de base e da compreensão do papel do complexo da saúde no modelo de desenvolvimento.

Essas são as questôes que se colocam para todos os modelos de proteção social em saúde e suas respostas serão diferenciadas segundo os modelos criados e as especificidades de cada momento histórico.

O modelo de proteção social da América Latina foi baseado no emprego formal, garantindo dois tipos básicos de benefícios: assistência à saúde, individual e curativa, e aposentadoria, pensões e benefícios ligados aos acidentes de trabalho. Esse modelo de seguro social, criado na metade do século 20 , tendo se iniciado por algumas categorias ocupacionais como a dos militares e professores, se expandiu enormemente com o crescimento econômico do período pós-1930 até meados dos anos 70, com características fortemente protetoras e pouco redistributivas, pois manteve sempre as posições da sociedade salarial. A redistribuição de recursos entre camadas da população e a mobilidade social aconteceram nesse período, mais por políticas econômicas de expansão do emprego, redistribuição dos ganhos de produtividade e tributação mais progressiva, e menos pela política social, tendo em vista seu atrelamento ao mercado formal de trabalho, no sentido de definir quem será protegido e de determinar os níveis de sustentabilidade e disponibilidade financeira do seguro social.

Com a crise no final dos anos 1970 e que perdurou até meados dos anos 1990, houve um desfinanciamento do modelo de seguro social, com destaque para crise da Previdência Social e da saúde no bojo da Previdência, quando os recursos escassearam e a forma de contratar serviços para provisão entrou em colapso, pela dificuldade de manter as margens de rentabilidade dos provedores privados, que são ampla maioria no caso da saúde.

A questão dos modelos universais não se colocou para América Latina e foi somente Brasil nos anos de 1980 que essa idéia entrou na agenda, por se tratar de 
uma conjuntura muito especial, de redemocratização e de crise e questionamento do antigo modelo de proteção social em saúde.

\section{O sistema de proteção social brasileiro: trajetória, características estruturais e especificidade da saúde}

Já é bem conhecido que o sistema de proteção social brasileiro, grosso modo, se estruturou predominantemente em bases designadas por autores clássicos que analisaram os Welfare States dos países avançados como corporativas (na tipologia de Esping-Andersen) ou meritocrático-particularistas (na tipologia de Titmuss) ${ }^{1}$. Tal modelo parte da premissa de que cada pessoa deve buscar resolver suas próprias necessidades, a partir de sua inserção no mundo do trabalho. As ações de proteção são em sua maioria estruturadas em função das categorias profissionais, entre as quais variam o escopo e a abrangência dos direitos ou benefícios sociais disponíveis. A política social tem caráter complementar às instituições econômicas, eventualmente corrigindo a ação do mercado.

No caso brasileiro, a partir de $1930^{2}$, à maior intervenção estatal na economia correspondeu um aumento da intervenção estatal na área social, sob um modelo específico. Para muitos analistas, o primeiro governo Vargas constitui um marco na configuração das políticas públicas no Brasil, estabelecendo um arcabouço jurídico e institucional que moldaria as políticas sociais até o período mais recente. Aureliano e Draibe (1989) designam esse momento como de "introdução" do sistema de proteção social brasileiro, ressaltando seu caráter delimitado em termos de áreas da política e grupos beneficiados. A política social do governo Vargas enfatizou a regulação do mundo do trabalho, destacando-se a legislação trabalhista e previdenciária, com a expansão de alguns direitos sociais aos integrantes de categorias profissionais do mercado de trabalho formal e urbano, estratégicas para o processo de desenvolvimento em curso.

Assim, desenvolveram-se políticas diferenciadas de reconhecimento dos direitos, constituindo-se institucionalmente o modelo fragmentado de proteção social. O padrão de incorporação de direitos sociais segmentado e desigual no período, no âmbito de um dado modelo de intervenção estatal, centralizado e autoritário, é bem resumido pelo conceito de "cidadania regulada", proposto por Santos (1979). Ainda que reconheça os avanços operados no plano da legislação protetora do trabalhador, Araújo (2003) alerta para uma limitação importante do modelo 
varguista, que foi a criação de várias "categorias de brasileiros", deixando de fora muitos grupos, sem sequer tocar na questão da terra e dos direitos rurais.

O sistema de proteção social brasileiro, para Aureliano e Draibe (1989), teria se expandido nas décadas subseqüentes, em termos de áreas das políticas e população beneficiária, porém sem que suas características fundamentais fossem alteradas até os anos 1980. Ainda que com variações entre as políticas, as autoras sinalizam que entre 1964 e 1985 teria se procedido à consolidação institucional e reestruturação conservadora daquele sistema de proteção construído a partir dos anos 1930, cujos traços seriam coerentes com o modelo econômico brasileiro, conservador e socialmente excludente.

Entre as características histórico-estruturais que conferem especificidade ao sistema de proteção social no Brasil, as autoras destacam: a extrema centralização política e financeira no nível federal das ações sociais do governo; a formidável fragmentação institucional; o princípio do autofinanciamento do investimento social; o princípio da privatização; a exclusão da participação da população nos processos de decisão (AURELIANO; DRAIBE, 1989).

Como essas características mais gerais do sistema de proteção social se expressavam na política de saúde? Considerando a abordagem de Lenhardt e Offe (1984), na análise das políticas sociais é importante considerar não somente sua inserção estrutural em um Estado capitalista, mas também as peculiaridades que as distinguem de outras políticas nos processos históricos das sociedades. $\mathrm{Ou}$ melhor, é importante compreender as especificidades relacionadas à evolução, modificações e inovações em uma dada política social, assim como a relação entre as estratégias de racionalização da ação estatal e as mudanças nessas políticas.

Sabe-se que a história da política de saúde no Brasil é anterior à década de 1930, tendo sido elemento importante na constituição do Estado Nacional ainda na Primeira República (LIMA; FONSECA; HOCHMAN, 2005). A partir dos anos 1930, a condução da política de saúde no Brasil passa por mudanças importantes. A primeira delas é de fato o movimento de nacionalização da política, qual seja, de configuração de estruturas nacionais de autoridade. Conformam-se no período dois ministérios que passam a dividir a responsabilidade pela saúde: o Ministério da Educação e Saúde Pública (MESP), que comanda as ações de saúde coletiva, de caráter mais universal; e o Ministério do Trabalho, Indústria e Comércio (MTIC), ao qual se ligava a assistência médica previdenciária, dirigida aos grupos 
de trabalhadores inseridos no mercado formal de trabalho urbano (HOCHMAN; FONSECA, 1999; FONSECA, 2007).

É certo que existem diferenças na lógica de relacionamento federativo e no grau de centralização/descentralização das decisões, observadas entre essas duas estruturas nacionais e ao longo do tempo. No entanto, a análise da trajetória da política de saúde nas décadas subseqüentes revela, grosso modo, o predomínio de uma lógica de condução centralizadora de poder, coerente com o processo mais geral de conformação de um Executivo federal forte, que se afirmou como um traço constitutivo marcante do Estado brasileiro no século XX (ALMEIDA, 2007). Nos anos 1980, a primeira característica do sistema de proteção social brasileiro destacada por Aureliano e Draibe (1989) - a centralização política e financeira - se expressava nitidamente tanto na condução dos programas verticais pelo Ministério da Saúde como na lógica de atuação do Instituto Nacional de Assistência Médica da Previdência Social (INAMPS), responsável pela assistência médica previdenciária.

Quanto à segunda característica do sistema de proteção social brasileiro apontada por Aureliano e Draibe (1989) - a fragmentação institucional -, vale apontar que, além da dualidade representada pela existência de durante cinco décadas de dois ministérios que dividiam responsabilidades sobre as ações de saúde, havia marcante fragmentação no interior de cada um desses ramos. Isso pode ser exemplificado pela existência de vários Institutos de Aposentadorias e Pensões, ligados à Previdência Social e estruturados por categorias profissionais. Ao longo do período, sucessivas reformas administrativas somente reiteraram o quadro de fragmentação institucional. Os debates sobre a unificação do comando sobre a política nacional de saúde, embora presentes em alguns momentos históricos - como na criação do Ministério da Saúde em 1953 (HAMILTON; FONSECA, 2003) - contrariavam interesses, o que impediu a conformação de uma política de saúde única e articulada. Ao final dos anos 1980, a fragmentação institucional se expressava fortemente no setor, com divisão de responsabilidades não apenas entre os Ministérios da Saúde e da Previdência Social, mas entre diversos órgãos e entidades com diferentes vinculações e formas jurídicas, como o Instituto Nacional de Assistência Médica da Previdência Social (INAMPS), a Fundação Serviços de Saúde Pública (FSESP), a Superintendência de Campanhas de Saúde Pública (SUCAM), a Central de Medicamentos (CEME) e a Fundação Oswaldo Cruz (FIOCRUZ), entre outras, que atuavam de maneira pouco integrada entre si. Outro aspecto importante da fragmentação institucional 
apontada pelas autoras reside na falta de integração entre os modelos de assistência à saúde e as redes de serviços dos três entes governamentais com superposição de níveis de atenção, pouca economia de escala e racionalidade técnica, fato que até os nossos dias carece de solução.

O terceiro traço marcante do sistema de proteção social brasileiro - o princípio do autofinanciamento -, segundo Aureliano e Draibe (1989), diz respeito à submissão do gasto social a critérios econômicos e financeiros de rentabilidade privada e à noção de que os usuários deveriam pagar pelo que recebem. Ainda que mais nítida em outros setores ${ }^{3}$, essa característica também se expressou na saúde, particularmente na vertente da assistência médica previdenciária. Isso porque a Previdência se estruturou em uma lógica de capitalização, típica de seguro social, sendo que o acesso aos benefícios sociais dependia da contribuição de empregadores e empregados, recolhida sobre a folha de salários. Ademais, Oliveira e Teixeira (1989) relatam episódios de deslocamento de recursos da Previdência, quando era superavitária, para o atendimento de interesses econômicos (como a construção de estatais) ou mesmo a anistia de dívidas de empresários junto à Previdência como incentivo a investimentos em áreas estratégicas da economia. Já em momentos de déficit da Previdência, os trabalhadores sofrem pressões relacionadas ao aumento das contribuições ou restrições aos benefícios ou serviços, o que podia afetar a assistência médica previdenciária. Uma conseqüência desses arranjos é o caráter altamente regressivo do financiamento social, inclusive na saúde, com repercussões nas décadas subseqüentes.

A quarta característica - o "princípio" da privatização - decorreu de uma divisão de trabalho entre Estado e setor privado em que o primeiro estabelecia regras e fornecia recursos, enquanto o segundo assumia a prestação de serviços sociais. $\mathrm{Na}$ vertente da assistência médica sob comando da Previdência, esse movimento foi marcante de meados dos anos 1960 aos anos 1980. Nesse período, ocorreu progressiva expansão do acesso da população aos serviços de saúde propiciada pelo financiamento estatal para a compra de serviços hospitalares privados e mesmo linhas de investimento para a construção de hospitais privados (OLIVEIRA; TEIXEIRA, 1989). Outro mecanismo que se inicia já nessa época são os subsídios estatais indiretos, como a isenção fiscal de gastos das empresas com assistência à saúde de seus empregados. Ou seja, por meio de diversas estratégias, a atuação do Estado no período induz e financia a configuração de um complexo médico-industrial (CORDEIRO, 1984; 
BRAGA; PAULA, 1986) e de um sistema de saúde com relações imbricadas e por vezes perversas entre o público e o privado.

A quinta característica estrutural do sistema de proteção social brasileiro apontada por Aureliano e Draibe (1989) é a exclusão da população dos processos decisórios sobre a política, por meio da supressão da participação de sindicatos, partidos e movimentos sociais em vários domínios da política social. Isso se relacionou à expansão do sistema de proteção sob governos, marcados pelo centralismo autoritário e burocrático. $\mathrm{Na}$ saúde, essa característica se expressou tanto na vertente previdenciária como na da saúde pública. Como exemplo, pode-se mencionar que o movimento de rediscussão sobre as políticas de saúde que vinha sendo empreendido no período democrático, a partir de 1945 e que culminou em ampla discussão na III Conferência Nacional de Saúde de 1963, foi bruscamente interrompido pelo golpe militar de 1964 (GERSCHMAN; VIANA, 2005).

As cinco características gerais do sistema de proteção social brasileiro descritas também influenciaram outro elemento, este mais específico da saúde: a configuração do modelo de atenção à saúde. Ressalte-se que a expressão "modelo de atenção à saúde" pode usada em vários sentidos. Ainda nos anos 1980, Oliveira e Teixeira (1989) utilizaram o termo "modelo médico-assistencial privatista", para designar de forma abrangente a conformação hegemônica do sistema de saúde brasileiro então observada, caracterizada por: centralização política, administrativa e financeira; privilegiamento das atividades curativas, em particular as hospitalares, em detrimento das ações de promoção da saúde e prevenção das doenças; privilegiamento da contratação de hospitais privados ao invés do fortalecimento do setor público; ineficiência e ineficácia em termos de resultados sanitários.

Em trabalho recente, Paim (2004) adotou o termo "atenção à saúde" em sentido bastante amplo, apontando que o seu exame pode se dar a partir de dois enfoques: (1) como resposta social aos problemas e necessidades de saúde, inserindo-se no campo disciplinar da política de saúde, em que podem ser identificadas as ações e omissōes do Estado; (2) como um serviço compreendido no interior dos processos de produção, distribuição e consumo, inserido no setor terciário da economia, dependendo de processos que perpassam os espaços do Estado e do mercado. Essa conceituação considera, além da dimensão social, a dimensão econômica do setor saúde, ressaltando que o sistema de serviços de saúde é alvo de pressões para consumo de mercadorias, que podem ou não ser necessárias para o atendimento das 
necessidades. Ao ampliar o conceito, o autor alerta para todo um campo que necessariamente deve ser objeto de atenção do Estado na condução da política pública de saúde. Essa era essencialmente uma das principais bandeiras do movimento pela reforma sanitária brasileira da década de 1980: a transformação do modelo de atenção à saúde hegemônico até então, de forma que as políticas passassem a se orientar uma concepção de saúde abrangente e pelas necessidades de saúde da população, fundadas na noção da saúde como direito social de cidadania.

Após essa breve explanação sobre as principais características histórico-estruturais do sistema de proteção social brasileiro que marcaram a configuração das políticas de saúde até os anos 1980, cabe perguntar: em que medida o projeto representado pelo SUS, em seus vinte anos de implantação, teve força para transformar tais características da proteção social em saúde no país?

\section{O Sistema Único de Saúde: mudanças e continuidades na proteção social em saúde}

Existem numerosos estudos de balanço da implementação do SUS que tratam de temas específicos, relevantes para a proteção social em saúde. Os temas da descentralização e do controle social em saúde, por exemplo, têm sido objeto de um grande número de pesquisas e publicações, envolvendo discussões densas, que não serão tratados neste artigo ${ }^{4}$. Neste tópico do texto, ainda que não se pretenda esgotar os debates presentes em vasta literatura, é feito um breve balanço das mudanças observadas nos últimos vinte anos em quatro dimensões selecionadas relevantes para a proteção social em saúde: organização institucional; financiamento; relações público-privadas e modelo de atenção à saúde.

\section{Reorganização e fragmentação institucional}

A conformação de uma política nacional de saúde única e articulada era um aspecto importante da agenda da reforma sanitária brasileira, embora não houvesse consenso mesmo entre os grupos progressistas sobre o modelo organizacional mais adequado para a coordenação da Seguridade Social e do SUS 5 .

Nos vinte anos de implementação do SUS, de fato houve mudanças organizacionais importantes na condução da política, expressas em dois movimentos simultâneos: a unificação horizontal do comando sobre a política nacional, com vistas à configuração de uma autoridade sanitária federal única; e a 
descentralização político-administrativa, com redistribuição vertical de poder e fortalecimento de milhares de autoridades sanitárias no país, representadas pelas Secretarias Estaduais e Municipais de Saúde. Tais movimentos foram influenciados tanto pela agenda da reforma sanitária como por outra agenda de reforma do Estado, de inspiração liberal, que foi hegemônica na década de 1990.

O processo de reordenamento institucional relacionado ao comando nacional do SUS, foco deste texto, não foi linear, podendo ser identificados diferentes momentos.

Um primeiro momento, de 1990 a 1992, pode ser designado como de formação inicial do novo Ministério da Saúde. O principal marco desse momento é incorporação do INAMPS "vivo" ao Ministério da Saúde, preservando funções importantes de normatização e financiamento. Observam-se no período tensões entre grupos favoráveis e contrários à extinção dessa entidade. Apesar da permanência do INAMPS no interior do Ministério da Saúde ser apontada com um ícone da resistência à transformação institucional necessária à implantação do SUS, as mudanças operadas na estrutura ministerial no período não foram desprezíveis. A nova Secretaria Nacional de Assistência à Saúde (SNAS) - cujo secretário acumula a Presidência do INAMPS - assume responsabilidades progressivamente maiores na coordenação nacional de políticas de assistência à saúde, incorporando aos poucos atribuições do antigo Ministério da Saúde - como a responsabilidade sobre as políticas de saúde mental, tuberculose e câncer - e do INAMPS - como a atribuição de gerir os sistemas de alta complexidade. A existência dentro dessa secretaria de um "Departamento do SUS", por outro lado, denota uma visão enviesada do SUS como uma parte da política de saúde, bem como a dificuldade de transformação institucional do Ministério da Saúde no novo gestor federal do SUS. Outra mudança importante é a constituição da Fundação Nacional de Saúde (FUNASA), por meio da incorporação da Fundação Serviços de Saúde Pública (FSESP) e Superintendência de Campanhas de Saúde Pública (SUCAM). A FUNASA passa a coordenar nacionalmente as ações de controle de endemias e epidemias.

Um segundo momento, de 1993 a 1996, de reestruturação organizacional próunificação, é caracterizado pela extinção do INAMPS e progressivo fortalecimento da Secretaria de Assistência à Saúde (SAS). Uma transformação de grande relevância é o início do funcionamento do Fundo Nacional de Saúde como principal caixa de entrada e saída dos recursos do setor saúde, geridos pelo Ministério da Saúde. A SAS passa a concentrar o comando das atividades do INAMPS, dos vários programas 
de atenção anteriormente coordenados pelo antigo Ministério da Saúde e de novas estratégias prioritárias, como a de Saúde da Família ${ }^{6}$. Assim, no interior da SAS nos anos subseqüentes convivem diferentes legados institucionais, com distintas lógicas de formulação das políticas e organização dos programas e ações de saúde (por tipo de serviço, por nível de complexidade, por grupo populacional, por agravo, entre outras). Ressalte-se ainda que tal secretaria passa a ser responsável pela gestão de políticas e programas que correspondem a maior parte dos gastos federais da saúde (cerca de 90\%, na maioria dos anos subseqüentes).

$\mathrm{O}$ ano de 1997 representa um momento peculiar de enxugamento e fragmentação institucional, influenciado tanto pela agenda mais geral de reforma do Estado, como pela visão dos dirigentes federais sobre as atribuições do Ministério da Saúde. Destaque-se a extinção do Instituto Nacional de Alimentação e Nutrição (INAN) e a desativação da Central de Medicamentos (CEME), atribuídos a diferentes motivos, entre os quais se sobressai o argumento da necessidade de descentralização das ações dessas estruturas para estados e municípios ${ }^{7}$. A incorporação da responsabilidade de coordenação nacional das atividades do INAN e da CEME ao Ministério se dá de forma fragmentada, por meio de diversos programas em diferentes órgãos do Ministério, sejam os anteriormente existentes ou em novas secretarias criadas. Observase também um esforço de redução do poder da Secretaria de Assistência à Saúde (SAS), com transferência de parte de suas atribuiçôes à recém-criada Secretaria de Políticas de Saúde (SPS). Isso ocorre em relação ao comando do processo de descentralização, de alguns programas de atenção básica e de parte da assistência farmacêutica, enquanto outras ações de atenção à saúde permanecem sob responsabilidade da SAS. Pode-se dizer que a criação da SPS favorece uma fragmentação da atenção à saúde que será aprofundada nos anos subseqüentes.

O quarto momento, de 1998 a 2002, é marcado pelo aprofundamento da fragmentação institucional historicamente fundada e reiterada no momento anterior. Mas a importância de considerar esse período separadamente reside no fato de que, nesse período, as mudanças na estrutura do Ministério expressam uma expansão de atividades que não era percebida em 1997, o que permite designálo como um momento de diversificação de açôes e fragmentação institucional. As principais mudanças na estrutura administrativa do Ministério da Saúde nesse período são: (a) a criação de duas agências reguladoras de segmentos de mercados em saúde: a Agência Nacional de Vigilância Sanitária e a Agência Nacional de 
Saúde Suplementar (esta precedida pela criação do Departamento de Saúde Suplementar - DESAS - no âmbito da SAS), que surgem em um contexto mais geral de reforma do Estado e criação de agências reguladoras, porém com especificidades na saúde; (b) a criação de novos departamentos (incluindo o Departamento de Atenção Básica), com redivisão de atribuições entre Secretaria de Assistência à Saúde e Secretaria de Políticas de Saúde, agravando a fragmentação na condução da política nacional de atenção à saúde e da política de descentralização; (c) a criação da Secretaria de Gestão de Investimentos em Saúde; (d) a ampliação das atribuições da Secretaria Executiva.

Um quinto momento pode ser identificado a partir de 2003, em vigor até os dias atuais (final de 2008). Tal período é marcado pelo esforço de reestruturação organizacional por áreas de atuação, visto que sua ênfase é na reorganização do Ministério com base na natureza dos objetos dos vários campos de intervenção em saúde. Ressalte-se a conformação da nova Secretaria de Atenção à Saúde por meio da unificação das secretarias de Assistência à Saúde e de Políticas de Saúde, o que representou um esforço de reduzir a fragmentação no comando das ações de atenção.

Vale ainda destacar a conformação de três novas secretarias: a de Ciência, Tecnologia e Insumos Estratégicos; a de Gestão da Educação e do Trabalho em Saúde; e a de Vigilância em Saúde ${ }^{8}$. A criação das duas primeiras secretarias têm significado como esforço de maior institucionalização de dois campos estratégicos de atuação do Estado na saúde que nos anos 1990 expressaram importantes lacunas de atuação federal: o de insumos e o de recursos humanos. Já a criação da Secretaria de Vigilância em Saúde trouxe para a administração direta do Ministério o comando nacional das políticas de vigilância epidemiológica, área estratégica da saúde pública até então sob o comando da Fundação Nacional de Saúde (FUNASA). Assim, representou um movimento de, ao mesmo tempo, reduzir as atribuições e o poder da FUNASA e fortalecer o campo da vigilância epidemiológica, por meio de proposições de expansão do seu escopo e da maior articulação com estratégias de promoção da saúde. As áreas de vigilância sanitária e de regulação da assistência médica suplementar permaneceram sob o comando das duas agências reguladoras da saúde (a ANVISA e a ANS) e a Fundação Oswaldo Cruz manteve, como nos momentos anteriores, suas atribuições diversificadas na área de ensino, pesquisa, desenvolvimento científico e tecnológico e produção de insumos em saúde.

De forma geral, as mudanças na estrutura do Ministério a partir de 2003 
contribuíram para um desenho institucional que parece mais adequado ao desenvolvimento de açôes nos vários campos de atenção à saúde, embora não se tenha solucionado o problema da fragmentação interna - que tem raízes históricas antigas -, os conflitos de poder e a persistência de estruturas obsoletas, sem que problemas estruturais do SUS sejam enfrentados?.

\section{Expansão, estabilidade e descentralização no financiamento público}

O financiamento da política de saúde muda radicalmente com a emergência do SUS, quando pela primeira vez, o gasto público em saúde passa a ser financiado não mais pela contribuição de empregados e empregadores e sim por impostos dos três níveis de governo e contribuiçôes sociais arrecadadas pelo nível federal e repassada para os ministérios da área da seguridade social.

O financiamento do gasto público em saúde, isto é, a operação do SUS, como definido pela Constituição Federal de 1988, envolve o compromisso das três esferas de governo - federal, estadual e municipal; de um lado; de outro, depende das regras de partilha do Orçamento da Seguridade Social (OSS) entre saúde, previdência e assistência social. Sendo assim, o estabelecimento de regras claras de participação de cada esfera governamental e de regras justas e equilibradas de partilha no interior do OSS, são vitais para uma maior eficiência do modelo.

O primeiro regramento só foi definido no início de 2000, com a EC 29, quando essa definiu percentuais mínimos (escalonados) sobre a receita arrecadada para o gasto em saúde dos estados e municípios, e um percentual de aumento para o gasto federal segundo variações nominais do PIB.

O segundo está até hoje está sem definição e é um alvo e elemento preferencial da política fiscal (seja porque é usado para cobrir despesas correntes da União ou por que é fonte dos fundos de estabilização). Isto é, é recorrente o uso dos recursos da SS para outros fins.

Com isso o movimento ascendente da principal fonte do OSS, nos anos 90, as Contribuiçõos Sociais (Contribuição para o Financiamento da Seguridade Social (COFINS), a Contribuição sobre o Lucro Líquido de Empresas (CSLL) e a Contribuição Provisória sobre a Movimentação Financeira (CPMF), esta última a partir de 1997, não resultou em maiores recursos para saúde. As mesmas passaram a financiar outros tipos de gastos federais, como forma de compensar a perda de receita tributária da esfera federal para estados e municípios desde 
1988 (são fontes não compartilháveis com estados e municípios como são os impostos diretos e indiretos). E ainda passaram a ser fontes importantes do Fundo Social de Emergência (FSE-1994/96), posterior Fundo de Estabilização Fiscal (FEF-1996/1999) e hoje Desvinculação das Receitas da União (DRU), instrumentos de contingenciamento do orçamento fiscal.

Dessa forma, quando se examina a evolução do gasto social federal por área de atuação, observa-se que a participação dos gastos com saúde se mantém quase constante no período assinalado, em torno de $14,1 \%$ do gasto total no período 1995-2005, conforme o IPEA.

Em suma, a substituição das fontes tributárias por receitas de contribuição, evidenciado na inexpressiva participação das receitas do Tesouro no financiamento do gasto público federal em saúde, e o uso dessas fontes para compensar perdas de receita e manter os compromissos do ajuste fiscal, explicam a estagnação do gasto federal em saúde (2,1 e 1,9\% do PIB, no início e final da década). Melhor dizendo, o financiamento da saúde foi peça importante na consecução das metas de política econômica (ajuste fiscal) e não respondeu às necessidades da implantação de um sistema de saúde universal.

Como o gasto público em saúde conta com recursos de estados e municípios, foi justamente o incremento da participação dessas esferas de governo que permitiu o incremento do gasto público nos anos 90 e na primeira década do século XXI. Dados do IPEA mostram que a média de participação dos recursos próprios estaduais e municipais no financiamento público da saúde na década de 80 foi de $25 \%$. Em 1995, a participação ascende para 37,2\%; e, segundo o Ministério da Saúde, nesse mesmo ano, essa participação foi de 41,2\%.

Entre 1994 e 1996, os gastos dos municípios com saúde apresentam crescimento de quase $85 \%$ (fonte IPEA), e essa tendência se manteve até os anos recentes.

Sublinhe-se que a regulamentação da participação das esferas governamentais no gasto público em saúde definida pela EC29 - estados e municípios alocaram a partir de 2000, pelo menos $7 \%$ das receitas resultantes de impostos e transferências constitucionais para área da saúde e esse percentual cresceu gradativamente até atingir 12\% para os estados e 15\% para os municípios - aportou recursos adicionais, porém como os mesmos estão condicionados pela evolução das receitas públicas estaduais e municipais e do crescimento econômico (os aporte federais deverão ser corrigidos pela variação nominal do PIB), o gasto público em saúde passa a 
ter um caráter cíclico, isto é, acompanha o crescimento econômico e é muito variável no território brasileiro.

Os dados recentes indicam justamente esse movimento, quando por conta do maior desenvolvimento econômico dos anos recentes, houve aumento dos aportes de recursos dos níveis estadual e municipal para o gasto público em saúde, porém com grandes diferenciações segundo regiōes, mesmo dentro dos estados da federação e por porte de municípios.

A disponibilidade de recursos financeiros (seja recursos próprios ou a receita total per capita) é uma variável chave para explicar a variação na oferta de serviços de saúde no território nacional, Sublinhe-se que a literatura internacional também aponta que o sucesso do processo de descentralização é altamente dependente da disponibilidade de fundos para o cumprimento das atribuições e prioridades locais (PHRplus, 2004) ${ }^{10}$. Sendo assim, são condicionantes do processo de descentralização as regras que informam a disponibilidade de recursos no nível local para o gasto em saúde. Como se sabe, essas são definidas pelas regras que presidem a partilha de recursos entre esferas de governo, isto é, o modelo de federalismo fiscal e os critérios que regulam as transferências federais e estaduais para a operacionalização do SUS (LIMA, 2007).

Sublinhe-se que tanto a implantação do SUS quanto o modelo de federalismo fiscal adotado no Brasil são fenômenos interligados em sua origem, pois ambos foram criados no momento de mudança da ordem constitucional, isto é, são frutos da Constituição Federal de 1988.

O caso brasileiro de descentralização, por sua vez, apresenta inúmeras particularidades, decorrentes do modelo de federalismo fiscal adotado na Constituição Federal de 1988, da herança do modelo anterior de federalismo fiscal (partilhas definidas pela reforma tributária de 1966/67) e, finalmente, do perfil de formação do produto/renda no território nacional. Dessa forma, a federação brasileira se destaca, segundo os estudiosos do tema do federalismo fiscal:

1) pela forte descentralização das competências tributárias, pois se atribui ao nível intermediário à competência do principal imposto sobre o consumo (ICMS estadual);

2) por uma imensa disparidade inter-regional (as regiões mais pobres têm arrecadação per capita três vezes menor do que as regiões mais ricas);

3) pela grande autonomia dos governos subnacionais.

Por outro lado, a descentralização efetuada na Constituição Federal de 1988 não 
foi acompanhada por descentralização planejada de encargos (é bom lembrar que o nível municipal assumiu inúmeros encargos ao longo do processo de descentralização, porém esse processo não foi planejado), por um lado; por outro, privilegiou a esfera municipal, pois foi esse nível de governo que teve sua participação na capacidade de gasto efetivamente ampliada nas duas últimas décadas. Segundo Prado et al. (2003), por isso a descentralização de encargos derivada também tomou esse rumo, o que os autores denominam de Lei de Say fiscal, isto é, a receita tende a gerar seu próprio gasto. E, finalmente, nas palavras dos autores, manteve os governos estaduais com a mesma situação de vinte anos atrás, quando comparado com a situação atual, do ponto de vista das atribuiçôes de encargo como da disponibilidade líquida de recursos após as transferências intergovernamentais.

As mudanças introduzidas na Constituição Federal de 1988 mudaram a equação de distribuição de recursos em prol dos estados e, principalmente, dos municípios, obrigando a União a utilizar impostos e contribuições sociais (principal fonte de financiamento da saúde) não compartilhados com os estados e municípios para financiar seus gastos, o que colocou em prática, nas palavras de Rezende e Oliveira (2003), um processo desordenado de descentralização de encargos sem o estabelecimento de regras claras de cooperação financeira dessas esferas, fator indispensável para garantir a sustentação financeira de políticas públicas nas áreas de saúde, educação, infra-estrutura urbana, etc. (REZENDE; OLIVEIRA, 2003).

Assinale-se que somente após a edição da EC-29 o financiamento da saúde passou a ser definido pela regra, porém a mesma é baseada na disponibilidade líquida de recursos de cada ente governamental. Isso evidencia que a oferta de serviços e ações é fortemente dependente da extração de recursos próprios por cada ente governamental, isto é, da base econômica existente, e das transferências dos níveis federal, estaduais e setorial - portanto, essa disponibilidade é bastante diversa no território nacional.

Até 1998, vale a afirmação de que as regras de distribuição dos recursos do SUS para estados e municípios, ao serem definidas pelo critério de produção de serviços (oferta) - apesar de ter sido introduzida, em 1996, uma nova modalidade baseada no critério populacional (Piso de Atenção Básica), porém ainda incipiente, nesse período, quando comparado ao volume de recursos alocado para custeio da prestação - impediam que o caráter redistributivo se efetivasse, pois eram as regióes mais desenvolvidas que mais produziam procedimentos e, portanto, mais recebiam. 
Atualmente, por conta das transferências previstas pelo Piso da Atenção Básica (PAB fixo, ampliado e variável) e de outros tipos de transferências para os Fundos Estaduais de Saúde, bem como as emendas parlamentares, é crescente a participação das regiōes Nordeste e Norte nas transferências totais do SUS.

Este perfil de distribuição de recursos (pelas regras de partilha do modelo de federalismo fiscal e setorial, isto é, interno ao SUS) para o financiamento do gasto público em saúde impôs um padrão de oferta de serviços muito diferenciado no território nacional e é hoje um obstáculo crescente à construção de políticas regionais dentro do SUS. Assinale-se, ainda, que esse perfil de financiamento da área da saúde é um dos traços, referente ao desempenho do sistema público de saúde, mais paradoxal, pois, ao possibilitar a implantação descentralizada das ações de saúde, impede a constituição de instrumentos que contribuam para diminuir os quadros de desigualdades regionais e de iniqüidades na oferta e no acesso aos serviços de saúde.

Por fim, esse modelo de federalismo fiscal propiciou o crescente relacionamento direto da União com os municípios, o que induziu o esvaziamento da capacidade dos governos estaduais na função de coordenação das atividades intermunicipais e ampliou a possibilidade de conflito no relacionamento intergovernamental.

Do ponto de vista do financiamento interno ao SUS, também este modelo induziu a uma predominância de relações de tipo bilaterais (federal-municípios; estadual-federal; estadual-municípios) e a resistência à criação de espaços de relacionamento, articulação e negociação multilaterais. Tomem-se como exemplo as dificuldades para a criação de uma política regional no interior do SUS, em decorrência do fato de que a simples criação de espaços regionais implica necessariamente o estabelecimento de articulações e negociações multilaterais.

Com isso manteve-se uma característica forte do modelo anterior, isto é, alta centralização de recursos e uma rígida divisão intergovernamental, cenário pouco favorável a um real processo de descentralização, ao estabelecimento de um novo tipo de relacionamento entre esferas de governo, entre público e privado e de maior cooperação entre políticas setoriais.

\section{Convivência e tensões entre o público e o privado na saúde}

Nas últimas duas primeiras décadas de implantação do SUS, houve mudanças importantes nas relações público-privadas em saúde que, no entanto, não 
alteraram uma característica histórico-estrutural marcante do sistema de saúde brasileiro: a forte presença do setor privado, promovida e apoiada pelo Estado, com imbricadas - e por vezes perversas - relações entre o público e o privado na saúde, perpetuadoras de desigualdades sociais.

As relaçóes público-privadas em saúde podem ser analisadas sob diversas perspectivas. Neste texto, serão feitas algumas consideraçóes relativas à composição público-privada do gasto em saúde; ao mix público-privado na oferta de serviços diretamente financiados pelo Estado; ao segmento de assistência médica suplementar; e às novas relações entre público e privado, expressas nas mudanças nos modelos de gestão de serviços de saúde.

Vinte anos após a Constituição, o Brasil continua a apresentar um peso importante dos gastos privados na composição do gasto setorial e gastos privados em termos per capita bem superiores aos gastos públicos (BAHIA, 2005 e 2008), o que é pouco condizente com o modelo universal representado pelo SUS e reflete problemas estruturais do mix público-privado no país. Ainda que estimativas de especialistas sugiram que no Brasil mais da metade dos gastos são de origem privada, ou seja, desembolsados pelas empresas ou famílias ${ }^{11}$, vale ressaltar que parte desses gastos é subsidiada pelo Estado, mediante renúncia fiscal e outros mecanismos.

No âmbito da oferta de serviços, houve expansão importante da quantidade de serviços públicos no período de implantação do SUS, principalmente à custa do aumento de serviços municipais de caráter ambulatorial, com um menor aumento de hospitais públicos municipais. A oferta de serviços privados sem internação consultórios, clínicas e principalmente serviços de apoio diagnóstico e terapêutico - também cresceu de forma expressiva, havendo certa redução do número de estabelecimentos hospitalares e de leitos privados no país entre 1992 e 2005 (IBGE, 2005). Parte expressiva desses serviços privados é contratada e paga pelo Estado para prestar serviços à população, sendo que a prestação de serviços hospitalares no SUS ainda é predominantemente privada. Muitos dos serviços privados que são contratados pelo Estado também prestam serviços a operadoras de planos e seguros de saúde, têm planos próprios (por exemplo, as Santas Casas) e recebem por desembolso direto dos usuários.

Ressalte-se ainda a existência no Brasil de um segmento de assistência médica suplementar cujas origens remontam aos anos 1960 e cujo crescimento foi expressivo nas décadas de 1970 e 1980 (CORDEIRO, 1984; BAHIA, 1999), que continua a 
apresentar um dinamismo importante mesmo após a instituição do SUS. Dados recentes apontam a existência de cerca de 44,7 milhões de beneficiários de planos de saúde no país, sendo 36,9 milhões de assistência médica, o que corresponde a 19,8\% da população brasileira (ALBUQUERQUE et al, 2008). Segundo os autores, entre 2000 e 2006 - período em que os dados sobre o segmento passam a ser mais confiáveis - houve pequeno aumento da cobertura populacional estimada.

A cobertura do segmento, no entanto, é extremamente variável entre os estados e municípios, sendo que a maior concentração de beneficiários encontra-se em somente 30\% dos municípios do país - em geral os de maior porte das regiōes Sudeste e Sul - que concentram 70\% da população (ALBUQUERQUE et al, 2008). Os mesmos autores apontam que, apesar da existência de mais de mil operadoras, grande parte dos beneficiários está concentrada em poucas operadoras. Tal segmento também é altamente diversificado, no que diz respeito à natureza dos planos (coletivos, que são a maioria, ou individuais), tipo de cobertura (ambulatorial ou hospitalar, com ou sem obstetrícia e cobertura odontológica), redes de serviços e benefícios disponíveis (que variam de acordo com "níveis" dos planos oferecidos pelas operadoras).

Estudos sugerem que os beneficiários de planos e seguros de saúde dispõem de maior acesso aos serviços do que a população que não tem plano, seja pela maior disponibilidade da oferta de alguns tipos de serviços e equipamentos nesse segmento, seja pela cobertura duplicada que o segmento oferece em relação ao sistema público de saúde (SANTOS; UGÁ; PORTO, 2008).

A partir de 1998, com a promulgação da "Lei dos Planos de Saúde" (BRASIL, 1998) e a posterior criação da Agência Nacional de Saúde Suplementar, o segmento de assistência médica suplementar passa a ser regulado pelo Estado. As principais linhas de atuação da ANS a partir de 2000 são: o levantamento, a organização e a sistematização de informações sobre o segmento de planos e seguros de saúde; o estabelecimento de regras para elaboração de novos contratos; o estabelecimento de limites de variação de preços dos planos por faixa etária e para reajustes periódicos de preços de planos individuais; o estabelecimento de normas referentes ao patrimônio e segurança financeira das empresas de planos e seguros de saúde; a implementação de mecanismos de ressarcimento das operadoras ao SUS, que não chega a funcionar adequadamente. Em outras palavras, grosso modo a atuação da ANS se direciona principalmente à organização do mercado de assistência médica suplementar e à 
adoção de alguns mecanismos de proteção aos consumidores.

Publicação recente aponta como um dos resultados da regulação estatal no período de 2000 a 2006 a maior solidez das operadoras e o aumento no número de beneficiários (SANTOS; MALTA; MERHY, 2008). Por outro lado, especialistas da área questionam o modelo de regulação adotado, argumentando que questôes estruturais importantes relativas às relações público-privadas na saúde - as isenções fiscais, as implicaçôes do interesse do capital financeiro na área - não têm sido enfrentadas (ANDREAZZI; KORNIS, 2003; REIS, 2005). Alerta-se ainda para as contradições entre a forma de atuação do Estado junto a esse segmento, cujo dinamismo chama a atenção, e o projeto político representado pelo SUS (BAHIA, 2008).

Outro aspecto relevante diz respeito às novas modalidades de articulação entre público e privado no âmbito dos serviços de saúde, expressas nos novos modelos de gestão e de contratação dos profissionais que proliferam a partir dos anos 1990, principalmente nos hospitais públicos. Alguns exemplos são as novas formas de vinculação jurídico-institucionais das unidades, as terceirizações de diversos tipos, as fundações privadas de apoio e a contratação de cooperativas de profissionais de saúde (MACHADO, 2001). Ainda que com diferenças importantes entre si, algumas dessas experiências alteram as relações entre público e privado de forma substantiva, ao introduzirem mecanismos de mercado ou diferenças no acesso e no fluxo de atendimento a diferentes clientelas - pessoas que têm ou não planos privados de saúde - no interior de serviços anteriormente estatais e públicos.

\section{Mudanças e impasses no modelo de atenção à saúde}

Após o início da implantação do SUS, houve avanços expressivos no modelo de atenção no âmbito de políticas específicas, como os relacionados às políticas nacionais de combate à Aids e de saúde mental ${ }^{12}$. No entanto, a grande mudança ocorrida foi uma ênfase crescente nas açōes de atenção básica, com a emergência do Programa de Saúde da Família em 1994 e seu incremento maciço a partir de 1998, porém mais evidente em algumas regiōes do país e em municípios de menor porte populacional.

Este movimento de privilegiar a configuração do sistema de saúde com base na atenção básica - de certa forma antecipando-se aos desígnios posteriores de OMS e OPAS, que definem em 2007/08 os sistemas baseados em atenção 
primária como o eixo norteador de sua agenda política - contou com vigorosos mecanismos de incentivos financeiros, institucionais e para formação, especialização e capacitação de profissionais mais adequados aos requisitos técnicos desse nível de atenção.

No caso brasileiro, a estratégia nacional para a atenção básica esteve inserida no bojo de um projeto de construção de um sistema de saúde baseado nas diretrizes de universalidade e integralidade de atenção, o que a princípio favoreceu o predomínio de uma concepção abrangente de atenção primária na construção da política, mesmo no contexto político-econômico desfavorável dos anos 1990 .

Entretanto, análises recentes sobre a implantação das estratégias da atenção básica/expansão da saúde da família evidenciam inúmeros problemas na organização, eficiência e efetividade da atenção básica no SUS, incluindo fragilidades no âmbito do modelo de atenção. Campos (2007), por exemplo, argumenta que a dimensão da clínica vem sendo subestimada no âmbito da estratégia de saúde da família. Já o trabalho de Conill (2008) destaca que permanecem dificuldades no acesso, na estrutura física, na formação das equipes, na gestão e na organização da rede de atenção básica, que se correlacionam com o baixo patamar de financiamento público, a persistência de segmentação no sistema e a fraca integração dos serviços de atenção básica com outros níveis de atenção.

Os desafios no âmbito do modelo de atenção à saúde no SUS ficam ainda mais evidentes nas pesquisas voltadas para os grandes centros urbanos, que concentram atualmente a maior parte da população brasileira. Os estudos de linha de base do Projeto de Expansão e Consolidação do Saúde da Família (PROESF), conduzidos nacionalmente nos anos de 2005 a 2007, mostraram que alguns desafios à expansão e consolidação da Atenção Básica e do Programa Saúde da Família (PSF) nos municípios com mais de 100 mil habitantes não decorrem somente dos desafios enfrentados pelo próprio setor saúde, mas também da seletividade das modernizações inerentes à complexa dinâmica da urbanização brasileira, pois as metrópoles abrigam um paradoxo: as melhores infra-estruturas e os mais altos índices de riqueza com a desigualdade e a impossibilidade de acesso de muitos cidadãos aos serviços públicos.

No contexto das metrópoles, o esforço de consolidação e expansão da atenção básica como primeira porta de entrada do cidadão às ações de saúde mostra-se como uma estratégia prioritária para minimizar essas desigualdades, ao mesmo 
tempo em que as dificuldades dessa consolidação não deixam de refletir os próprios desafios do SUS para a universalização da saúde diante da diversidade e complexidade do território brasileiro.

São características dos grandes centros e dos municípios em áreas metropolitanas, modelos com diferentes combinações do mix público-privado na atenção básica, o que pode ser explicado, dentre outros fatores, pelas maiores densidades técnicas, científicas, informacionais que abrigam, isto é, densidade populacional concentrada em uma área conurbada que conforma um amplo mercado de consumo no setor saúde, o que atrai investimentos privados de toda ordem; serviços de saúde de média e alta complexidades e com maior número de especialidades; centros de formação e pesquisa de excelência em saúde; além de profissionais atraídos pelo mercado de trabalho, pelas condições de formação e pelos recursos que as metrópoles e seu entorno oferecem para a vida urbana.

Municípios fora das regiōes metropolitanas, mas que estão em pleno processo de modernização e densificação técnica, científica, informacional e populacional, também seriam localidades com maior propensão para abrigarem, atualmente ou num futuro próximo, variados graus de inter-relações entre o setor público e uma lógica privada/mercantil de acesso aos serviços, mesmo aqueles mais básicos. Levando-se em consideração o crescimento dos planos de saúde entre as classes $\mathrm{C}$ e D da população, é possível pensar que esse fator também irá influenciar sobremaneira os modelos de Atenção Básica.

Ao mesmo tempo, a política de $\mathrm{AB}$ deve associar-se a uma política de desenvolvimento urbano, pois questôes como transporte, habitação e saneamento básico, por exemplo, têm reflexos importantes nas condiçôes de vida e saúde da população. O sistema de saúde, como uma política setorial isolada, não consegue acompanhar a complexidade urbana atual. Além disso, o financiamento e o planejamento estratégico do sistema têm que considerar as adversidades e as novas demandas geradas nas grandes cidades.

Outro problema decorre da baixa eficácia de organização dos serviços de saúde no nível da $\mathrm{AB}$ (ausência de planejamento, de sistemas de monitoramento e avaliação, pouco uso dos indicadores extraídos dos diferentes sistemas de informação), revelando que os sistemas municipais de saúde e os gestores municipais enfrentam grande dificuldade para planejar e pactuar suas açōes, levando em consideração uma dinâmica regional de uso dos serviços e demandas por serviços 
de saúde. Dinâmica que resulta da constante integração econômica e social entre os municípios das regiões metropolitanas, pois é cada vez maior a fluidez de pessoas e mercadorias entre esses municípios.

Provavelmente, os municípios das áreas metropolitanas não tenham condições técnicas e informacionais para lidar com essa complexidade da dinâmica urbana regional. A baixa eficácia dessas localidades pode ser um dos fatores cruciais para explicar as dificuldades de pactuação intermunicipal das açôes de Atenção Básica. Tal dificuldade acarreta, entre outras coisas, em uma baixa efetividade do sistema de saúde nas regiōes metropolitanas. É por esse motivo que as políticas de saúde, sobretudo, de Atenção Básica, não podem estar dissociadas de uma política regional de saúde, assim como de uma política global de desenvolvimento urbano.

\section{Considerações finais}

A Constituição brasileira de 1988, como destacou Eleutério Rodriguez Neto, representou um momento de "aferição das regras para o início, de fato, de uma nova etapa do processo; um novo patamar para as lutas políticas e sociais" (RODRIGUEZ NETO, 2003, p. 92). O reconhecimento formal da saúde como direito de cidadania, inserida em uma lógica abrangente de Seguridade Social, foi uma conquista muito expressiva, que desencadeou nas décadas subseqüentes uma série de transformações políticas, institucionais e organizacionais no sistema de saúde brasileiro.

Vinte anos depois, fazer um balanço dos avanços e limites da saúde na perspectiva da proteção social não representa tarefa simples. Isso porque a análise das dimensões relevantes para a proteção social selecionadas revela que, em meio à intensidade das transformaçôes operadas, permanecem ou se reeditam sob novas roupagens distorções histórico-estruturais importantes da proteção social em saúde no Brasil. Na organização institucional, por exemplo, houve várias mudanças relevantes, sem que se superasse a histórica fragmentação na condução nacional da política de saúde.

No âmbito do financiamento, os pequenos ganhos em termos de estabilidade não significaram um aumento substantivo no aporte de recursos para o setor saúde, nem tampouco a superação das imensas distorções do financiamento setorial, que se relacionam a questôes mais gerais do federalismo fiscal e à persistência de desigualdades no gasto, registradas entre os âmbitos público e privado e entre diferentes regiōes e localidades do país. 
No que se refere às relações público-privadas, as contradições são ainda mais evidentes, uma vez que paralelamente à expansão de um sistema público forte se observa a consolidação de mercados privados em saúde dinâmicos e fortes, sob incentivo do Estado, com a persistência de iniqüidades que colidem com a noção da saúde como direito de cidadania.

Por fim, no que concerne ao modelo de atenção à saúde, observam-se numerosos desafios, muitos dos quais relacionados aos problemas que persistem nas demais dimensões analisadas. Tal diagnóstico corrobora a tese de que o novo modelo de proteção social em saúde não conseguiu romper com uma dualidade presente desde a Primeira República e não superada pelo modelo do seguro social: o da convivência de forma isolada de dois modelos assistenciais produtivos em saúde, compreendidos como o resultado de uma específica integração entre a forma de organização dos serviços de saúde e o complexo produtivo em saúde, conformado por entidades públicas e privadas fornecedoras de bens e insumos para a realização das atividades de promoção, prevenção e assistenciais.

O SUS incorpora dois modelos assistenciais produtivos: um primeiro que inicia sua implantação na Primeira República e que permanece até os dias atuais, o de saúde pública, complementado por uma rede descentralizada de serviços ambulatoriais municipais/estaduais e apoiado por Institutos de Pesquisas/ Laboratórios Públicos, produtores de soros, vacinas e medicamentos (com destaque para a produção da Fiocruz e do Instituto Butantã). O segundo é desenvolvido após a emergência do sistema previdenciário, em 1930, composto por uma rede hospitalar com ênfase na oferta privada e com alta dependência tecnológica externa em todos os segmentos do complexo industrial da saúde e provedora de serviços, primeiro para Previdência, depois para o SUS e hoje também para as operadoras de saúde (planos e seguros).

Ambos os modelos convivem no SUS e sua integração é dificultada por uma série de motivos, entre outros, pela natureza distinta dos equipamentos/serviços presentes em um e outro, pela adoção de diferentes modalidades de prestação, acesso e financiamento e pela presença de diferentes grupos de atores na base política de sustentação desses arranjos.

As estratégias de enfrentamento dessa dualidade - seja pelo lado das políticas de descentralização/regionalização; ou pelas alterações no perfil de financiamento que penalizaram os municípios, porém sem mudar os perfis de gasto público per capita; 
ou mesmo pelas regras e regulações propostas; ou pela ênfase na atenção básica - não conseguiram ainda integrar esses dois modelos assistenciais produtivos.

Explicações possíveis para esse fenômeno, impeditivo da constituição de um sistema nacional integrado, público e universal, talvez se liguem ao processo político de constituição dos modelos e dos atores presentes em defesa de interesses específicos, cuja trajetória é não se unir em prol de uma rede única, possivelmente por medo de terem seus interesses atingidos ou por terem outra perspectiva para a política de saúde que não é o fortalecimento explícito de um sistema nacional.

Até o momento, na implantação do SUS pouco se enfrentou esse dilema organizacional e político, e também poucas estratégias foram pensadas para que esse quadro se alterasse substancialmente. Isso implicaria uma mudança radical no perfil de financiamento e gasto público em saúde - o que vai muito mais além da instabilidade ou insuficiência - revelando uma impotência dos gestores do sistema em desatar nós históricos e que não mudam nem mesmo com a emergência de um modelo de proteção social em saúde mais solidário e igualitário.

\section{Referências}

ALMEIDA, Célia Maria de. As Reformas Sanitárias dos Anos 80: Crise ou Transição. 1995.437 p. Tese (Doutorado), ENSP/FIOCRUZ, Rio de Janeiro, 1995.

ALBUQUERQUE, Ceres et al. A situação atual do mercado de saúde suplementar no Brasil e apontamentos para o futuro. Revista Ciência e Saúde Coletiva, v. 13, n. 5, p.1421-1430, 2008.

ALMEIDA, Maria Hermínia Tavares. O Estado no Brasil Contemporâneo. Um passeio pela história. In: Melo, Carlos Ranulfo; Sáez Manuel Alcântara (orgs). A Democracia Brasileira. Balanço e perspectivas para o século XXI. Belo Horizonte: UFMG, 2007, p. 17-31.

ANDREAZZI, Maria de Fátima Siliansky; KORNIS, George Eduard Machado. Transformações e desafios da atenção privada em saúde no Brasil nos anos 90. Physis: Revista de Saúde Coletiva, Rio de Janeiro, v. 13, n. 1, p. 157-101, 2003.

ARAUJO, M.C. Estado, classe trabalhadora e políticas sociais. In: FERREIRA, Jorge; DELGADO, Luciana de Almeida Neves (orgs.). O Brasil Republicano- O tempo do nacional-estatismo. Rio de Janeiro: Civilização Brasileira, 2003. p. 213-239.

AROUCA, Antônio Sérgio da Silva. O dilema preventivista: contribuição para a compreensão e critica da medicina preventiva. Tese (Doutorado)- Universidade Estadual de Campinas, Faculdade de Ciências Medicas, Campinas, SP, 1975. 
ARRETCHE Marta. Emergência e desenvolvimento do Welfare State: teorias explicativas. Revista Brasileira de Informação Bibliográfica em Ciências Sociais(BIB), v. 39, p. 3- 40, 1995.

ASHFORD, Douglas E. The British and French Social Security Systems: Welfare State by intent and by default. In:-- Ashford, Douglas E.; Kelley, E.W. (org), Nationalizing Social Security. Greenwich: JAI Press, 1986.

AURELIANO, Liana; DRAIBE, Sonia M. A especificidade do "Welfare State” brasileiro. In: Economia e Desenvolvimento. Brasília: CEPAL, 1989. p.85-178.

BAHIA, Ligia. Planos e seguros-saúde: padrões e mudanças das relações entre o público e o privado no Brasil. 1999. 333 f. Tese (Doutorado)-Escola Nacional de Saúde Pública, Fundação Oswaldo Cruz, Rio de Janeiro, 1999.

BAHIA, Ligia. O SUS e os desafios da universalização do direito à saúde: tensões e padrões de convivência entre o público e o privado no sistema de saúde brasileiro. In: LIMA, Nísia et al (orgs.). Saúde e democracia: história e perspectivas do SUS. Rio de Janeiro: FIOCRUZ, 2005. p. 407-449. BAHIA, Ligia. As contradições entre o SUS universal e as transferências de recursos públicos para os planos e seguros privados de saúde. Revista Ciência e Saúde Coletiva, v. 13, n. 5, p.1387-1397, 2008. BAPTISTA, Tatiana Wargas de Faria. Seguridade social no Brasil. Revista do Serviço Público, Brasília, DF, v. 49, n. 3, p. 99-118, 1998.

BORGES, Camila Furlanetti; BAPTISTA, Tatiana Wargas de Faria. O modelo assistencial em saúde mental no Brasil: a trajetória da construção política de 1990 a 2004. Cadernos de Saúde Pública, fev. 2008, v. 24, n. 2, p.456-468.

BRAGA, José Carlos de Souza; PAULA, Sérgio Goes de. Saúde e previdência: estudos de política social. 2. ed. São Paulo: HUCITEC, 1986.

BRASIL. Lei no 9656, de 3 de junho de 1998. Dispõe sobre os planos e seguros privados de assistência à saúde. Diário Oficial [da República Federativa do Brasil], Brasília, DF, 4 jun. 1998, p. 1. Disponível em: <http://www6.senado.gov.br/sicon/ExecutaPesquisaLegislacao.action>. Acesso em: 02 fev. 2005.

CAMPOS, Gastão Wagner de Souza. Reforma política e sanitária: a sustentabilidade do SUS em questão?. Revista Ciência e Saúde Coletiva, v. 12, n. 2, p. 301-306, abr 2007.

CASTEL, Robert. As metamorfoses da questão social: uma crônica do salário. 3. ed. Petrópolis: Vozes, 2001.

CASTRO, Jorge Abrahão de et al. Análise da evolução e dinâmica do gasto social federal: 19952001. Brasília: IPEA, 2003 (Texto para Discussão 988)

CONILL, Eleonor Minho. Ensaio histórico-conceitual sobre a Atenção Primária à Saúde: desafios para a organização de serviços básicos e da Estratégia Saúde da Família em centros urbanos do Brasil. Cadernos de Saúde Pública, v. 24, supl. 1, p. s7-s16, 2008. 
CORDEIRO, Hésio. As empresas médicas: as transformações capitalistas da prática médica. Rio de Janeiro: Graal, 1984.

CÔRTES, Soraya M.V. Construindo a possibilidade de participação dos usuários: conselhos e conferências no Sistema Único de Saúde. Sociologias, Porto Alegre, ano 4, n. 7, p.18-49, 2002.

DRAIBE, Sonia M. Uma nova institucionalidade das políticas sociais? Reflexões a respeito da experiência latino-americana recente de reformas dos programas sociais. São Paulo em Perspectiva, Fundação Seade, São Paulo, v. 11, n. 4, p. 3-15, 1997.

DRAIBE Sonia; RIESCO, Manuel. Estado de bienestar, desarrollo econômico y ciudadanía: algunas lecciones de la literatura contemporânea. México: Unidad de Desarrollo Social/CEPAL, 2006.

ENTHOVEN, Alain C. Reflections on the management of the National Health Service, London: Nuffield Provincial Hospitals Trust, 1985.

ESPING - ANDERSEN, Gosta. The Three Worlds of Welfare Capitalism. New York: Polity Press, 1990.

FERRERA, Maurizio. Modelli di Solidarietà. Itália: Il Mulino, 1993.

FONSECA, Cristina M. Oliveira. Saúde no Governo Vargas (1930-1945): dualidade institucional de um bem público. Rio de Janeiro: FIOCRUZ, 2007.

FREEMAN, Richard; MORAN, Michael. Reforming Health Care in Europe. In: FERRERA, Maurizio; RHODES, Martin. Recasting European Welfare States. London: Frankcass, 2000.

GERSHMAN, Silvia; VIANA Ana Luiza D’Ávila. Descentralização e desigualdades regionais em tempos de hegemonia liberal. In: LIMA, Nísia Trindade et al. Saúde e Democracia: história e perspectivas do SUS. Rio de Janeiro: FIOCRUZ, 2005, p. 307-351.

GIROTTI, Fiorenzo. Welfare State-storia, modelli e critica. Roma: Carocci, 2000.

GRANGEIRO, Alexandre et al. Sustentabilidade da política de acesso a medicamentos antiretrovirais no Brasil. Revista de Saúde Pública, v. 40, supl. , p. 60-69, abr. 2006.

HAMILTON, Wanda; FONSECA, Cristina. Política, atores e interesses no processo de mudança institucional: a criação do Ministério da Saúde em 1953. História, Ciências, Saúde-Manguinhos, Rio de Janeiro, v. 10, n. 3, p. 791-825, set./dez. 2003.

HOCHMAN, Gilberto; FONSECA, Cristina. O que há de novo?: Políticas de saúde pública e previdência, 1937-45. In: PANDOLFI, Dulce (org.). Repensando o Estado Novo. Rio de Janeiro: FGV, 1999. p. 73-93.

INSTITUTO BRASILEIRO DE GEOGRAFIA E ESTATÍSTICA. Pesquisa de Assistência MédicoSanitária MAS 2005. Disponível em: <www.ibge.gov.br>. Acesso em: 10 out. 2008.

LABRA, Maria Eliana. Capital social e consejos de salud en Brasil: un círculo virtuoso?. Cadernos de Saúde Pública, Rio de Janeiro, v. 18, p. S47-S55, 2002. 
LEICHTER, Howard M. A comparative approach to policy analysis: health care policy in four nations. Cambridge University Press: Cambridge, 1979.

LENHARDT, Gero; OFFE, Claus. Teoria do Estado e política social. In: OFFE, Claus. Problemas estruturais do Estado capitalista. Rio de Janeiro: Tempo Brasileiro, 1984. p. 10-53.

LIMA, Luciana Dias de. Federalismo, relações fiscais e financiamento do Sistema Único de Saúde: a distribuição de receitas vinculadas à saúde nos orçamentos municipais e estaduais. 1. ed. Rio de Janeiro: Museu da República, 2007. v. 1.352 p.

LIMA, Nísia Trindade; FONSECA, Cristina M. O.; HOCHMAN, Gilberto. A saúde na construção do Estado Nacional no Brasil: reforma sanitária em perspectiva histórica. In: LIMA, Nísia Trindade; GERSCHMAN, Silvia; EDLER, Flávio Coelho (orgs). Saúde e Democracia: história e perspectivas do SUS. Rio de Janeiro: Fiocruz, 2005, p.27-58.

MACHADO, Cristiani Vieira. Novos modelos de gerência nos hospitais públicos: as experiências recentes. Physis: Revista de Saúde Coletiva, Rio de Janeiro, v. 11, n. 1, p. 105-119, 2001.

MACHADO, Cristiani Vieira. Direito universal, política nacional: o papel do Ministério da Saúde na política de saúde brasileira de 1990 a 2002. Rio de Janeiro: Editora do Museu da República, 2007. MATTA, Gustavo Corrêa. A medida política da vida. A invenção do WHOQOL e a construção de políticas de saúde globais. 2005. 226f. Tese (Doutorado em Saúde Coletiva) - Instituto de Medicina Social, Universidade do Estado do Rio de Janeiro, Rio de Janeiro, 2005.

MATTOS, Ruben Araújo de. Desenvolvendo e ofertando idéias. Um estudo sobre a elaboração de propostas de políticas de saúde no âmbito do Banco Mundial. 2000. 307f. Tese (Doutorado em Saúde Coletiva) - Instituto de Medicina Social, Universidade do Estado do Rio de Janeiro, Rio de Janeiro, 2000.

MATTOS, Ruben Araújo de; TERTO JUNIOR, Veriano; PARKER, Richard. As estratégias do Banco Mundial e a resposta à AIDS no Brasil. Divulgação em Saúde para Debate, Londrina, n. 27, p. 81-94, 2003.

NORONHA, José Carvalho; LEVCOVITZ, Eduardo. AIS, SUDS, SUS: Os Caminhos do direito à saúde. In: . Saúde e sociedade no Brasil: anos 80. Rio de Janeiro: Relume-Dumará / ABRASCO/ IMS-UERJ, 1994. p. 73-111.

OLIVEIRA, Jaime A. de Araújo. Política social, acumulação e legitimidade: contribuição à história da previdência social no Brasil. 1981. Dissertação (Mestrado), Instituto de Medicina Social, Universidade do Estado do Rio de Janeiro, Rio de Janeiro, 1981.

OLIVEIRA, Jaime A. de Araújo; TEIXEIRA, Sonia M. Fleury. (Im)Previdência social: 60 anos de história da previdência no Brasil. 2.ed. Petrópolis, RJ: Vozes; Rio de Janeiro: ABRASCO, 1989.

PAIM, Jairnilson Silva. Atenção à saúde no Brasil. In: BRASIL. Ministério da Saúde. Saúde no Brasil: contribuições para a agenda de prioridades de pesquisa. Brasília: Ministério da Saúde, 2004. p.15-44. 
PHRplus (Partner for Health Reformplus). Monitoring and evaluation of decentralization reforms in developing country health sector (Prepared by Paul L. Hutchinson \& Anne K. LaFond), Maryland, 2004. POLANYI, Karl. A grande transformação. Rio de Janeiro: Campus, 1980.

PRADO, Sergio; QUADROS, Wladimir; CAVALCANTI, Carlos Eduardo. Partilha de Recursos na Federação Brasileira. São Paulo: Fapesp, Ipea , Fundap, 2003.

OCKÉ-REIS, Carlos Octávio. A reforma institucional do mercado de planos de saúde: uma proposta para criação de benchmarks. Brasília: IPEA, 2005.

REZENDE, Fernando. Apresentação. In: PRADO, Sergio; QUADROS, Wladimir; CAVALCANTI, Carlos Eduardo. Partilha de Recursos na Federação Brasileira. São Paulo: Fapesp, Ipea, Fundap, 2003.

REZENDE Fernando; OLIVEIRA, Fabrício Augusto. Descentralização e federalismo fiscal no Brasil. São Paulo: FGV/Konrad Adenauer Stiftung, 2003.

RIBEIRO, Patrícia Tavares. A descentralização da ação governamental em saúde no Brasil: revisitando os anos 90. 2007. 253 f. Tese (Doutorado em Saúde Coletiva)- Instituto de Medicina Social, Universidade do Estado do Rio de Janeiro, Rio de Janeiro, 2007.

RODRIGUEZ NETO, Eleuterio. Saúde: promessas e limites da Constituição. Rio de Janeiro: FIOCRUZ, 2003.

SANTOS, Wanderley G. Cidadania e justiça. Rio de Janeiro: Campus, 1979.

SANTOS, Nelson Rodrigues dos. A relação entre os órgãos executivos e o Conselho Nacional de Saúde na gestão do SUS: um relato comentado. Revista Saúde em Debate, Londrina, v. 27, n. 64, p. 148-152, 2003.

SANTOS, Isabela Soares; UGÁ, Maria Alicia Dominguez; PORTO, Silvia Maria. O mix públicoprivado no sistema de saúde brasileiro: financiamento, oferta e utilização de serviços de saúde. Revista Ciência e Saúde Coletiva, v. 13, n. 5, p.1431-1440, 2008.

SANTOS, Fausto Pereira dos; MALTA, Deborah Carvalho; MERHY, Emerson Elias. A regulação na saúde suplementar: uma análise dos principais resultados alcançados. Revista Ciência e Saúde Coletiva, v. 13, n. 5, p. 1463-1475, 2008.

TITMUSS, Richard. Social Policy. London: George Allen and Unwin. In: ABRUCIO, Fernando L. Descentralização e coordenação federativa no Brasil: Lições dos anos FHC. Brasília, mimeo, 2004.

VIANA, Ana Luiza D’ÁVILA et al. Descentralização no SUS: Efeitos da NOB 01/96. In: NEGRI, Barjas; VIANA, Ana Luiza D’ Ávila (orgs). O SUS em Dez anos de desafio. São Paulo: Sobravime/ Cealag, 2002.

VIANA, Ana Luiza D‘Ávila; LIMA, Luciana Dias; OLIVEIRA, Roberta Gondim de. Descentralização e federalismo: a política de saúde em um novo contexto - lições do caso brasileiro. Revista Ciência e Saúde Coletiva, Rio de Janeiro, v. 7, n. 3, p. 493-507, 2002. 
VIANA, Ana Luiza D‘Ávila.; DAL POZ, Mario Roberto. Estudo sobre o processo de reforma em saúde no Brasil. Informe Final para o Instituto Latinoamericano de Doctrina y Estudios Sociales/ILADES. (mimeo), 1998.

VIANA, Ana Luiza D’Ávila; MACHADO, Cristina Vieira. Descentralização e coordenação federativa: a experiência brasileira na saúde. Revista Ciência e Saúde Coletiva, 2009.

VIANNA, Maria Lucia T. Articulação de interesses, estratégias de bem-estar e políticas públicas: a americanização (perversa) da Seguridade Social no Brasil. 1995. Tese (Doutorado) -Instituto Universitário de Pesquisas do Rio de Janeiro, Rio de Janeiro, 1995.

WORLD BANK. World Development Report. Investing in health. Washington: World Bank, 1993.

WORLD BANK. Financing Health Services in Developing Countries: an agenda for reform. Washington: World Bank.

\section{Notas}

${ }^{1}$ Os diferentes autores utilizam critérios diversos para caracterizar os sistemas de proteção social e propor tipologias. É importante mencionar que a caracterização de um dado sistema como meritocrático-particularista, por exemplo, não significa que todas as políticas estejam estruturadas nessa lógica, podendo existir políticas com desenho mais universal ou residual.

${ }^{2}$ Alguns autores ressaltam como um marco importante na história da proteção social brasileira a instituição das Caixas de Aposentadorias e Pensōes, a partir da Lei Eloy Chaves, de 1923. Ver a propósito, Oliveira e Teixeira (1985).

${ }^{3}$ As autoras dão o exemplo típico do Banco Nacional de Habitação (BNH), que teria privilegiado o financiamento da habitação em detrimento do saneamento; e da habitação para a classe média em detrimento da habitação popular (AURELIANO; DRAIBE, 1989).

${ }^{4}$ A respeito dos avanços e limites da descentralização em saúde no período de implantação do SUS, ver por exemplo Levcovitz, Lima e Machado (2001), Viana, Lima e Oliveira (2002), Ribeiro (2007) e Viana e Machado (2009, no prelo). Sobre os desafios relacionados à participação e controle social no SUS, ver os trabalhos de Côrtes (2002), Labra (2002) e Santos (2003), entre outros. Os resultados de uma pesquisa nacional sobre conselhos municipais de saúde são apresentados em: http:// www.ensp.fiocruz.br/participanetsus_novo/

${ }^{5} \mathrm{O}$ modelo organizacional, que envolve a definição da autoridade/comando sobre a área social, é apontado por Vianna (1995) como uma das quatro dimensões relevantes para a caracterização da Seguridade Social em um dado país (as demais dimensões são a concepção, a abrangência e o financi- 
amento da Seguridade). Na Constituinte, ficou evidente a existência de conflitos entre os grupos progressistas ligados à Previdência e ao Ministério da Saúde sobre a estratégia para unificação institucional do comando da política de saúde, havendo um grupo que preferia a configuração de uma autoridade ampla para a Seguridade, à qual a política de saúde ficaria subordinada; e outro grupo que defendia a incorporação do INAMPS pelo Ministério da Saúde, que seria a autoridade sanitária nacional. Para o aprofundamento dessa discussão, ver os trabalhos de Noronha e Levcovitz (1994), Baptista (1998) e Rodriguez Neto (2003), entre outros.

${ }^{6} \mathrm{O}$ Programa de Saúde da Família é inicialmente criado vinculado à FUNASA (assim como já era o Programa de Agentes Comunitários de Saúde - PACS), mas em 1995, quando passa a assumir posição de destaque na agenda nacional, sua coordenação é transferida para a SAS.

${ }^{7}$ Em pesquisa realizada sobre a atuação do Ministério da Saúde nos anos 1990 (MACHADO, 2007), foram identificados três grupos de motivos para a extinção do INAN da CEME. O primeiro é a constatação de que ambos já teriam há muito se distanciado do seu papel, além de sofrerem acusaçôes de má-gestão e desvio de recursos. O segundo motivo seria a inadequação dessas estruturas centralizadas no contexto de descentralização das políticas de saúde. Um terceiro motivo tem relação com as próprias diretrizes de reforma do Aparelho de Estado no período, favoráveis à redução de estruturas federais e à descentralização, que permitem identificar 1997 como um ano de enxugamento da Administração Federal.

${ }^{8}$ Também foi criada a Secretaria de Gestão Participativa, porém baseada em outro argumento: a necessidade de transformar a relação entre Estado e sociedade por meio do fortalecimento das estratégias de participação e controle social na saúde, tema que não é discutido neste artigo.

${ }^{9}$ Mais recentemente, tem sido discutida a conformação de uma nova secretaria, que passaria a comandar as políticas relacionadas à atenção primária em saúde, promoção da saúde, saúde indígena e saneamento. A proposta tem sido justificada, por um lado, em função da necessidade de fortalecimento da atenção primária e da promoção da saúde; e por outro, na necessidade de transformar o modelo de gestão da saúde indígena. Ambos os argumentos encontram certo respaldo na análise da evolução organizacional do Ministério. Por exemplo, a progressiva ampliação do espaço da atenção básica na agenda federal ocorreu paralelamente a mudanças no status organizacional do comando dessa área, de programa para coordenação, de coordenação para diretoria. Já a atuação da FUNASA no comando das açôes da saúde indígena sempre foi alvo de profundas críticas. Vale ponderar, no entanto, que a proposta, caso concretizada, pode voltar a agravar a situação de fragmentação na condução das políticas federais, como observado em outros momentos. Ademais, uma motivação subjacente à criação da nova secretaria parece ter cunho essencialmente político: a crítica à concentração de grande poder e recursos sob o comando do Secretário de Atenção à Saúde, potencialmente geradora de tensões em um ministério que compreende outros cinco dirigentes de primeiro escalão.

${ }^{10}$ Segundo o documento citado, o sucesso do processo de descentralização depende ainda da capacidade técnica e administrativa do nível local; da operação de um sistema de monitoramento e accountability e, finalmente, de regras claras e transparentes que definam a divisão de responsabilidades entre os responsáveis pela política. Estudos recentes para o caso brasileiro atestam que a capacidade técnica e adminis- 
trativa do nível local é um processo seqüencial e de várias rodadas, na feliz expressão de Almeida e Abrucio, 2004, e constitui uma trajetória de aprendizado institucional (ver VIANA et al., 2002).

${ }^{11}$ Segundo dados da Pesquisa de Orçamentos Familiares (POF/IBGE), os gastos das famílias com assistência à saúde no Brasil representavam em 2002/2003, em média, 5,35\% das despesas das famílias brasileiras, sendo os principais itens de gasto os medicamentos, planos de saúde e tratamentos odontológicos, com peso variável de cada item entre as faixas de renda.

${ }^{12}$ Há um grande número de estudos sobre essas políticas. A respeito dos avanços e desafios da política nacional de Aids, ver entre outros Mattos, Terto e Parker (2003) e Granjeiro et al. (2006). Sobre as mudanças na condução nacional da política de saúde mental, ver por exemplo Borges e Baptista (2008). 


\section{Health Care Security: 20 years of the Unified Health System}

The creation of the Unified Health System by the 1988

Brazilian Constitution, based on the principle of universality and within a wide approach of Social Security, was an important alteration in the history of health care protection in Brazil. This paper presents a conceptual debate on health care protection and discusses the trajectory and main historical-structural characteristics of the Brazilian health care security up to the 1980's, emphasizing its health expressions. Then it analyzes the 20 years of the SUS, based on the analysis of changes and follow-ups in four dimensions selected to feature health care protection in Brazil: institutional organization; financing; public-private mix and health care model. Finally, it discusses the main difficulties and current challenges concerning the expansion of health care security in Brazil.

> Key words: health care security; Unified Health System; national health care policy; health care financing; public-private health care relations. 